\title{
Aneurisma adquirido de aorta ascendente em criança
}

Danton R. da Rocha LOURES*, Maria João Amorim FERREIRA*, Rui Sequeira de ALMEIDA*, Ronaldo Loures BUENO*, Antoninho KRICHENKO*, Paulo R. BROFMAN*, Edison José RIBEIRO*, Lauro LINHARES*, Mário Lobato da COSTA*, Edimara SEEGMULLER*

\section{RBCCV 44205-82}

LOURES, D. R. R.; FERREIRA, M. J. A.; ALMEIDA, R. S.; BUENO, R. L.; KRICHENKO, A.; BROFMAN, P. R.; RIBEIRO, E. J.; LINHARES, L.; COSTA, M. L.; SEEGMULLER, E. - Aneurisma adquirido de aorta ascendente em criança. Rev. Bras. Cir. Cardiovasc., 4(1): 94-99, 1989.

RESUMO: O aneurisma adquirido da aorta ascendente é uma rara condição na faixa pediátrica. Os autores apresentam 2 casos de crianças de 6 e 12 anos de idade com aneurisma sacular da aorta ascendente e estenose aórtica, os quais foram submetidos a correção cirúrgica, com sucesso.

DESCRITORES: aneurismas de aorta ascendente, cirurgia, crianças.

\section{INTRODUÇÃO}

O aneurisma da aorta ascendente em crianças é raro $^{5,6}$ e sua etiologia é difícil de estabelecer ${ }^{3}$.

Apesar de uma grande porcentagem dos aneurismas estar associada a trauma, lues, doença micótica, doença de Takayasu e síndromes de Turner e de Marfan, a causa mais freqüentemente apontada em crianças é a alteraçáo estrutural tardia de tecido artificial ou biológico empregado para correçăo de coartação da aorta.

São relatados 2 casos de crianças com aneurisma sacular da aorta associado a estenose aórtica, cuja etiologia é colocada em discussão.

\section{COMENTÁRIOS}

O aneurisma micótico ocorre por infecção da parede arterial $^{4}$ e pode ser causado por doenças infecciosas, endocardite bacteriana, ou contaminaçăo por procedimentos invasivos, quando o agente bacteriano causador da infecção não pode ser identificado ${ }^{1,2,4}$.
Os exames imunobacteriológicos excluem ou afirmam algumas etiologias, como sifilis, doença de Marfan, tuberculose, arterite. Nos casos apresentados, a avaliação do exame anatomopatológico năo ofereceu o diagnóstico, mas também nẫo excluiu a possibilidade da origem micótica.

Devido a estas considerações e pelo fato dos 2 pacientes terem apresentado, alguns meses antes, infecçōes (renal e endocardite bacteriana), a tendência seria admitir que a etiologia seja micótica. A afirmação estaria, também, baseada no fato de que aproximadamente $50 \%$ destes aneurismas, considerados como de etiologia micótica, apresentam culturas negativas ${ }^{1,2,4}$.

\section{RELATO DOS CASOS}

\section{Paciente de Número 1}

L. A. T., masculino, cor branca, 6 anos de idade.

História de síncope. dificuldade respiratória e cansaço ás mamadas, aos 10 dias de vida. Aos 3 meses,

Trabalho realizado no Hospital Evangélico de Curitiba. Curitiba, PR, Brasil. Recebido para publicaçáo em 20 de abril de 1989.

- Do Hospital Evangélico de Curitiba.

Endereço para s ’̧aratas: Danton R. da Rocha Loures. Rua Augusto Stellfeld, 2088. Bigorrilho. 80430 Curitiba, PR, Brasil. 
LOURES, D. R. R.; FERREIRA, M. J. A.; ALMEIDA, R. S.; BUENO, R. L.; KRICHENKO, A.; BROFMAN, P. R.; RIBEIRO, E. J.; LINHARES, L.; COSTA, M. L.; SEEGMULLER, E. - Aneurisma adquirido de aorta ascendente em criança. Rev. Bras Cir. Cardiovas., 4(1): 94-99, 1989.

apresentou cianose perioral e crises de hipóxia. Aos 19 meses, evoluiu com insuficiência cardiaca cor.gestiva sendo encaminhado ao nosso Serviço.

Segundo o relato, tinha dispnéia aos médios esforços, cansaço; pneumonia aos 3 meses de idade.

Apresentava estado geral regular e tórax discretamente abaulado. Frêmito sistólico em foco aórtico e fúrcula esternal e ausculta cardíaca com sopro sistólico de $4 / 6+$, audível em foco aórtico acessório e sopro sistólico de $2 / 6+$, em ponta de ventrículo esquerdo e foco mitral. Freqüência cardiaca de $120 \mathrm{bpm}$ e PA de $110 / 70$.

O exame radiológico do tórax mostrava circulação pulmonar normal e aumento global de área cardíaca às custas, principalmente, de ventrículo esquerdo.

O eletrocardiograma revelava ritmo sinusal, eixo desviado para a esquerda, alteraçóes difusas da repolarizaçăo ventricular, sobrecarga ventricular esquerda e presença de onda delta.

O cateterismo cardíaco realizado nessa ocasiāo (maio/81) evidenciou aumento moderado a importante das pressōes de capilar pulmonar e ventrículo direito. Importante aumento da pressão diastólica final de ventrículo esquerdo e gradiente pressórico entre ventrículo esquerdo e aorta de $55 \mathrm{mmHg}$. A cineventriculografia esquerda mostrou hipocinesia difusa com severo refluxo de contraste do ventrículo esquerdo para átrio esquerdo. Aortografia normal (Figura 1A).

Nessa ocasião, foi contra-indicada a cirurgia, por seu alto risco, voltando para a cidade de origem com diagnóstico de insuficiência mitral importante, dupla lesão aórtica com predomínio de estenose e miocardiopatia de grau moderado, sendo acompanhado cinicamente.

Aos 6 anos, apresentou novo quadro de insuficiência cardiaca congestiva, tendo, anteriormente, apresentado um quadro de infecção renal.

Foi compensado e reencaminhado para avaliaçăo cardiovascular.

Realizou novo cateterismo cardíaco (setembro/86) que, comparado com o anterior de 1981, evidenciou, ainda, pressōes elevadas em câmaras direitas de grau leve para moderado.

Houve desaparecimento da hipocinesia de ventriculo esquerdo e da insuficiência mitral. A aortografia mostrou aorta ascendente com dilatação pós-estenótica e a presença de aneurisma sacular no seu terço médio, com diâmetro aproximadamente igual ao da aorta (Figura 1B).

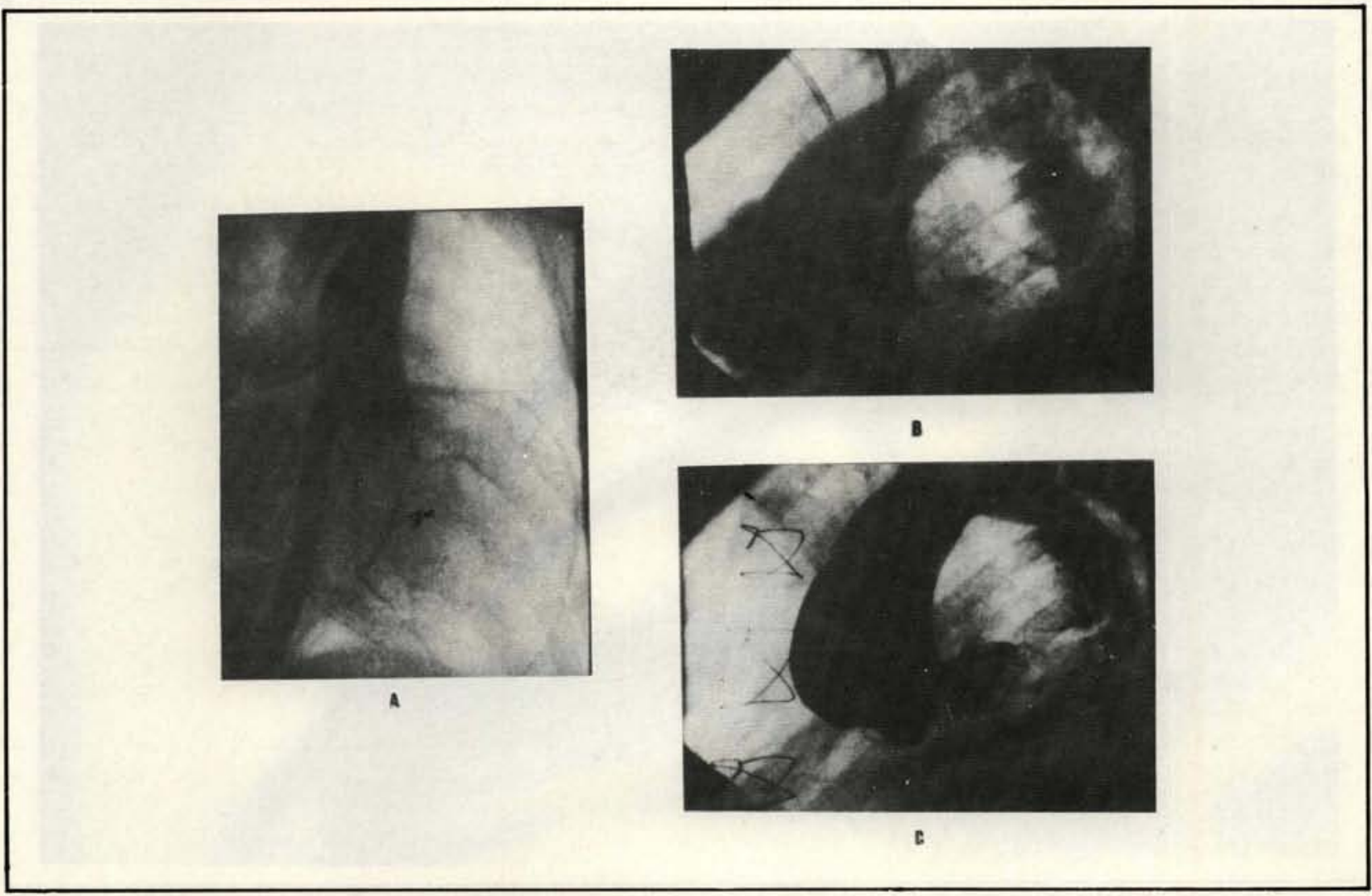

Fig. 1 - A: aortografia normal; B: aneurisma sacular da aorta ascendente; C: aortografia após a ressecçăo cirúrgica do aneurisma. 
LOURES, D. R. R.; FERREIRA, M. J. A.; ALMEIDA, R. S.; BUENO, R. L;; KRICHENKO, A.; BROFMAN, P. R.; RIBEIRO, E. J.; LINHARES, L.; COSTA, M. L.; SEEGMULLER, E. - Aneurisma adquirido de aorta ascendente em criança. Rev. Bras Cir. Cardiovas., 4(1): 94-99, 1989.

Foi submetido a cirurgia em 03.09.86, com auxilio da circulação extracorpórea, hemodiluição parcial, hiportemia moderada e uso de solução cardioplégica.

Apresentava a valva aórtica estenótica e bivalvulada com uma válvula embrionária. Realizou-se comissurotomia aórtica, ressecção do aneurisma sacular, que media $5 \times 4 \times 3 \mathrm{~cm}$ e reconstrução da aorta ascendente com pericárdio bovino (Figuras $2 \mathrm{~A}$ e $2 \mathrm{~B}$ e Figura 3 ).

O exame anatomopatológico revelou fibrose da camada média, discreta arteriosclerose e infiltrado crônico linfoplasmocitário. Na cultura, não houve crescimento de germes.

\section{O pós-operatório transcorreu normalmente.}

O exame radiológico de alta mostrava circulação pulmonar normal e diminuição importante da área cardíaca em relação ao estudo de pré-operatório, embora o ventrículo esquerdo estivesse aumentado.

\section{O eletrocardiograma não se modificou.}

O cateterismo cardíaco de controle e realizado no 10: dia de pós-operatório evidenciou normalizaçāo das pressōes em câmaras direitas e capilar pulmonar, pressão diastólica final do ventrículo esquerdo ainda aumen- tada e diminuiçăo importante do gradiente pressórico entre VE e Ao de 81 para $13 \mathrm{mmHg}$. Boa contratilidade ventricular esquerda. Valva aórtica de boa mobilidade com discreto refluxo para ventrículo esquerdo. Aorta ascendente dilatada com ausência de saco aneurismático (Figura 1C).

Um ano após a cirurgia, o paciente retornou para avaliação pós-operatória, encontrando-se totalmente assintomático. Ausculta com sopro sistólico e 2/6 + e sopro diastólico $1 / 6+$, ambos em foco aórtico.

\section{Paciente de Número 2}

M. R. K., sexo masculino, cor branca, 12 anos de idade.

História de sopro no coração identificada com idade de 3 anos, por ocasião de rubéola. Há 3 meses, apresentou quadro de endocardite bacteriana subaguda. $\mathrm{Fi}$ cou internado em hospital por um mês.

Apresentava estado geral regular e sem sintomas. O exame do precórdio evidenciava frêmito em região da fúrcula esternal, irradiado para o pescoço; sopro sisto. lico 5/6 \pm , audivel em foco aórtico acessório.

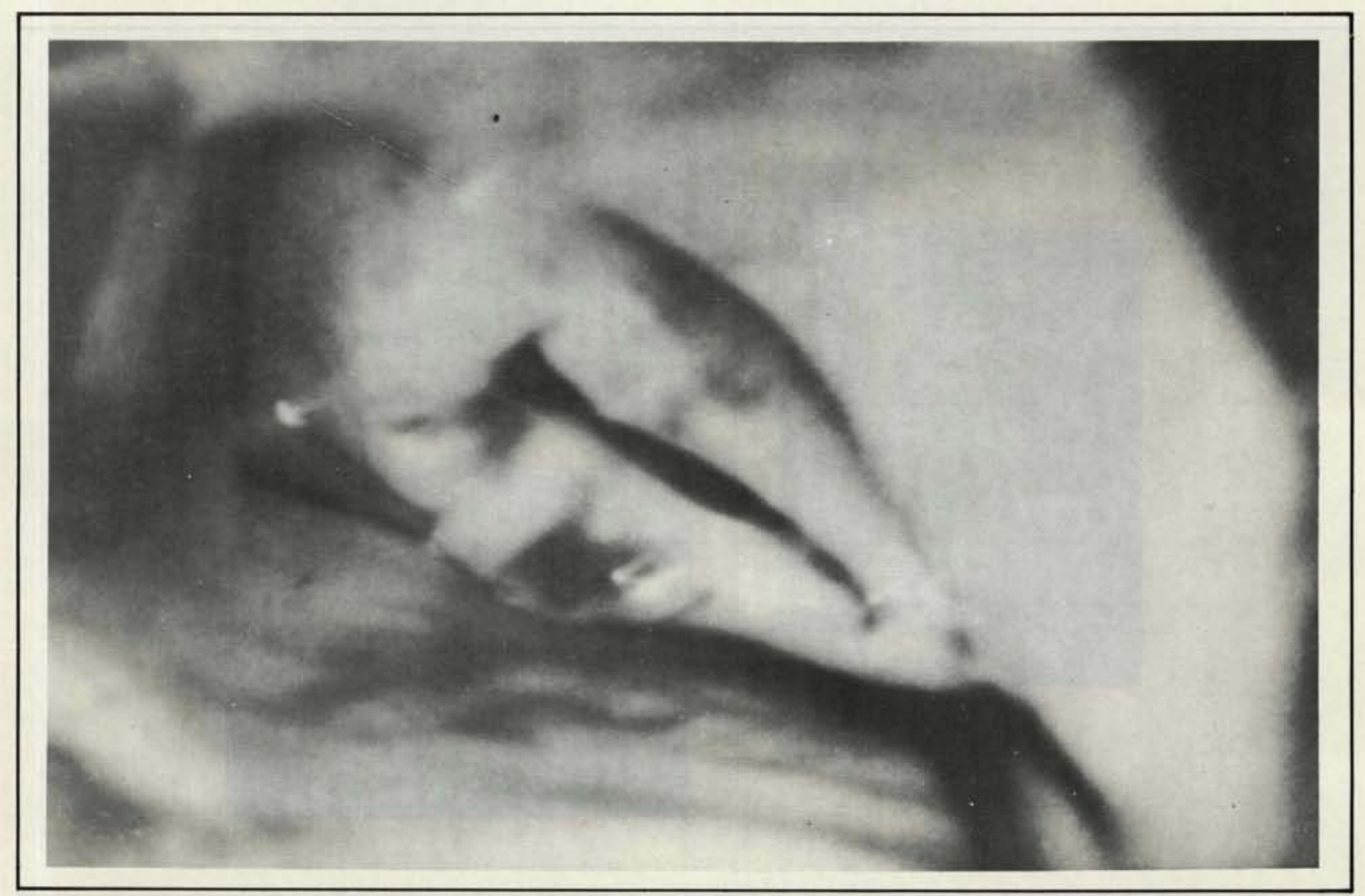

Fig. 2A — Foto intra-operatória. Valva aórtica-bivalvulada com 3: válvula embrionária e com estenose devido a fusâo comissural bilateral. 
LOURES, D. R. R.; FERREIRA, M. J. A.; ALMEIDA, R. S.; BUENO, R. L.; KRICHENKO, A.; BROFMAN, P. R.; RIBEIRO, E. J.; LINHARES, L.; COSTA, M. L.; SEEGMULLER, E. - Aneurisma adquirido de aorta ascendente em criança. Rev. Bras Cir. Cardiovas., 4(1): 94-99, 1989.

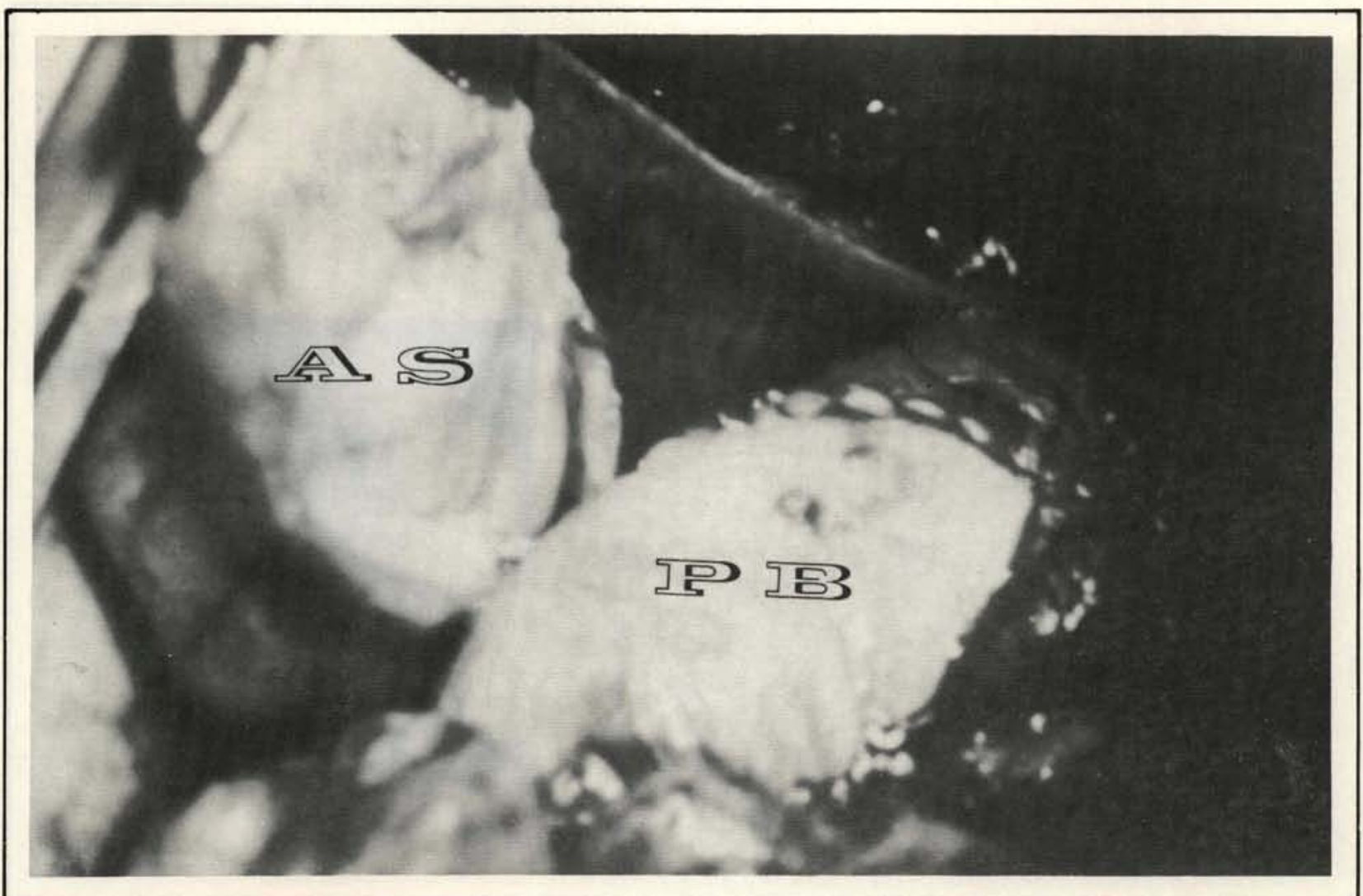

2B - Foto intra-operatória. Aorta ascendente após a ressecção do aneurisma sacular (AS); correção com placa de pericárdio bovino (PB).

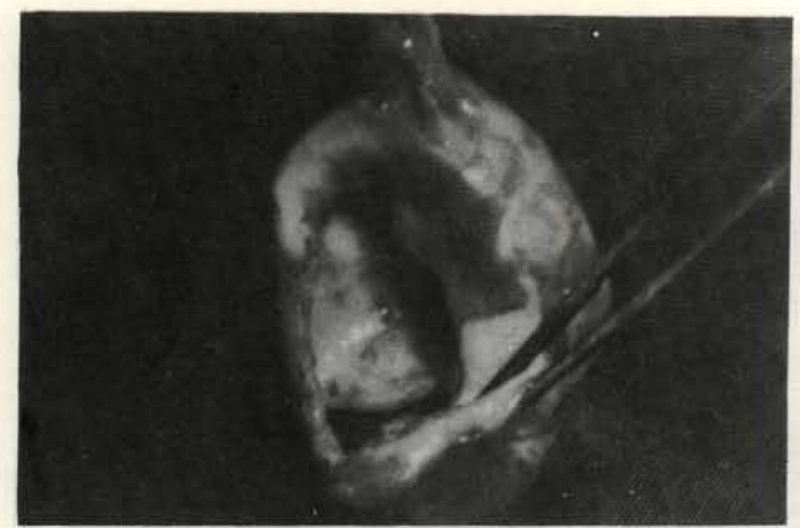

Fig. 3 - Segmento da aorta retirado.

Macroscopia: segmento de formaçăo aneurismática, medindo $5 \times 3 \times 3 \mathrm{~cm}$, com parede medindo $0,3 \mathrm{~cm}$ de espessura, sendo o revestimento interno liso e brilhante.

O exame radiológico mostrava circulação pulmonar normal e aumento discreto da área cardiaca, com sinais sugestivos de hipertrofia concêntrica de ventrículo esquerdo.

O eletrocardiograma evidenciava ritmo sinusal e sobrecarga importante do ventrículo esquerdo, com alteração difusa da repolarização ventricular.
O ecocardiograma bidimensional com Doppler, realizado em 06.03.89, confirmou estenose aórtica com gradiente entre ventrículo esquerdo e aorta e revelou imagem sugestiva de aneurisma sacular em aorta ascendente. O cateterismo realizado no mesmo dia confirmou estenose aórtica severa, funçāo ventricular esquerda adequada, valva mitral competente, gradiente entre ventrículo esquerdo e aorta de $171 \mathrm{mmHg}$ e 2 aneurismas saculares localizados no plano da valva aórtica e no terço inicial da aorta ascendente (Figura 4A, A1 e A2).

Foi submetido a cirurgia no dia seguinte com auxilio da circulaçăo extracorpórea, hemodiluiçăo parcial, hipotermia moderada e proteção miocárdica com solução cardioplégica cristalóide gelada a $4^{\circ}$ centígrados e soro gelado no pericárdio. A aorta mostrava dilataçōes saculares localizadas em aorta ascendente em níveis diferentes, respectivamente, no plano valvar na origem da coronária direita e $3 \mathrm{~cm}$ acima. Após a abertura da aorta, foi identificada valva ab́rtica bivalvulada calcificada e estenótica, anel aórtico pequeno, 2 aneurismas saculares sem trombos e paredes lisas (Figura 5A, B e C).

Os 2 aneurismas foram ressecados, a parede aórtica corrigida com placa de pericárdio bovino. $\mathrm{O}$ anel aórtico foi ampliado pela técnica de Manoughian, utilizando, também, pericárdio bovino e valva aórtica substituída 
LOURES, D. R. R.; FERREIRA, M. J. A.; ALMEIDA, R. S.; BUENO, R. L.; KRICHENKO, A.; BROFMAN, P. R.; RIBEIRO, E. J.; LINHARES, L.; COSTA, M. L.; SEEGMULLER, E. - Aneurisma adquirido de aorta ascendente em criança. Rev. Bras Cir. Cardiovas., 4(1): 94-99, 1989.

\section{NOME: MARCOS RODRIGO KLAUS}

DATA: 06.03 .89

\section{CAT $: 7867$}

IDADE : $12 \mathrm{a}$

A - MANOMETRIA: em mmHg

AD

$\begin{array}{cccc}\text { S } & \text { D } & \text { D } & \text { M } \\ 1 & 1 & 2 & \\ - & - & - & 9\end{array}$

VD

29

0

4

TP

29

9

$-18$

CP

VE

Ao

$\begin{array}{cccc}- & - & - & 9 \\ 253 & 0 & 7 & -\end{array}$

$82 \quad 58$

$-$

87

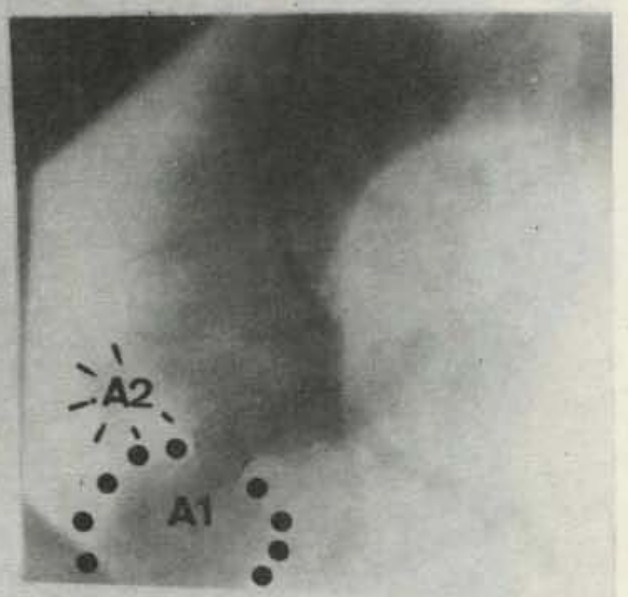

Fig. 4A - Estudo manométrico revelando estenose abrtica valvar com gradiente de $171 \mathrm{mmHg}$; A1 e A2: aortoqrafia revelando 2 aneurismas saculares de aorta ascendente.

$\mathrm{VE} / \mathrm{Ao}=$ ventrículo esquerdo/aorta.

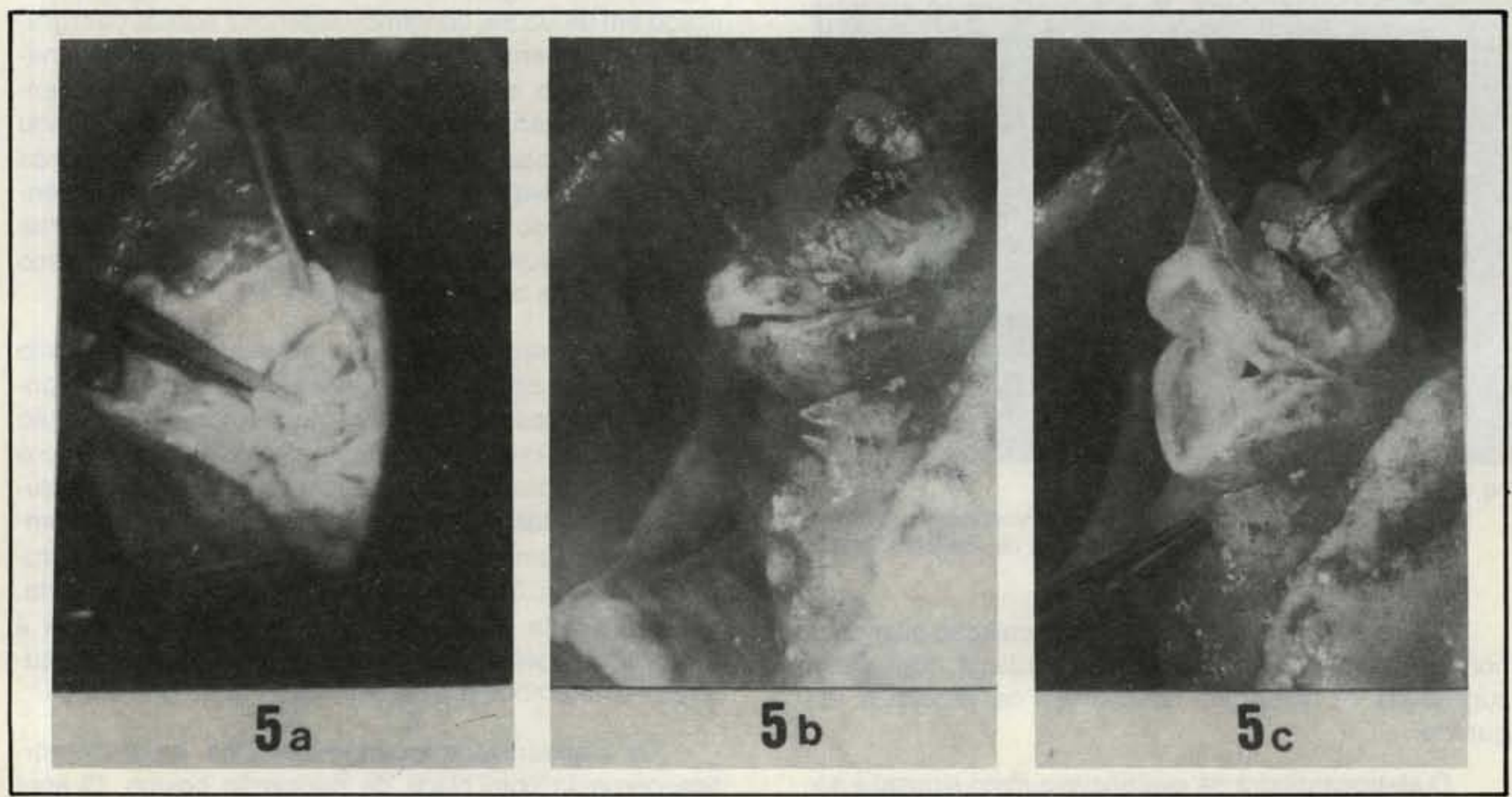

Fig. 5 - a: Aspecto transoperatório da valva aórtica trivalvulada e com estenose devida a fusăo comissural; b: aspecto de um dos focos aneurismáticos da aorta ascendente fechado; c: mesmo aneurisma aberto 
LOURES, D. R. R.; FERREIRA, M. J. A.; ALMEIDA, R. S.; BUENO, R. L.; KRICHENKO, A.; BROFMAN, P. R.; RIBEIRO, E. J.; LINHARES, L.; COSTA, M. L.; SEEGMULLER, E. - Aneurisma adquirido de aorta ascendente em criança. Rev. Bras Cir. Cardiovas., 4(1): 94-99, 1989.

por uma prótese artificial mecânica da Carbomedics n: 19.

\section{O exame anatomopatológico revelou:}

Macroscopia: 2 peças de forma sacular de aorta ascendente medindo $3 \times 2 \times 1 \mathrm{~cm}$ de paredes internas lisas sem trombos.

Microscopia: fibrose da camada média e infiltrado linfoplasmocitário. Na cultura nāo houve crescimento de germes. cações.

O pós-operatório imediato transcorreu sem compli-
O exame radiológico de alta hospitalar mostrava campos pleuropulmonares com aspecto radiológico normal.

O ECG apresentava-se sem modificações em relação ao do pré-operatório.

A ecocardiografia-Doppler revelou prótese aórtica normofuncionante com gradiente sistólico ventrículo esquerdo/aorta estimado em $38 \mathrm{mmHg}$.

Recebeu alta hospitalar no 8: dia de pós-operatório em condições clínicas satisfatórias. O controle clínico com 90 dias de pós-operatório revelou evolução favorável e sem sintomas específicos.

\section{RBCCV 44205-82}

LOURES, D. R. R.; FERREIRA, M. J. A.; ALMEIDA, R. S.; BUENO, R. L.; KRICHENKO, A.; BROFMAN P. R.; RIBEIRO, E. J.; LINHARES, L.; COSTA, M. L.; SEEGMULLER, E. - Acquired neurysm of the ascending aorta in children. Rev. Bras. Cir. Cardiovasc., 4(1): 94-99, 1989.

ABASTRACT: Acquired aneurysm of the ascending aorta is a rare condition in the pediatric age group. The authors present two cases of 6 and 12 year old boys with saccular aneurysm of the ascending aorta and aortic stenosis, which underwent successful surgical correction.

DESCRIPTORS: aneurysms of the ascending aorta, surgery, children.

\section{REFERÊNCIAS BIBLIOGRÁFICAS}

1 CHOYKE, P. L.; EDMONDS, P. R.; MARKOWITZ, R. I.; KLEIMAN, C. H. S.; LAKS, H. - Mycotic pulmonary artery aneurysm: complication of Aspergillus endocarditis. Am. J. Roentgenol., 138: 1172-1175, 1982.

2 COME, P. C.; SACKS, R.; VINE, H.; MCARDLE, C.; KORETSKY, S.; WEINTRAUB, R. - Ultrasonic visualization of the posterior thoracic aorta in long axis: diagnosis of a saccular mycotic aneurysm. Chest, 79: 470-472, 1981.

3 COOLEY, D. \& TAYLOR, F. M. - Aneurysm of thoracic aorta in an infant treated by resection and arterial homograft. J. Pediatr., 49: 185-190, 1956.
4 FIRT, P.; HEJNAL, J.; KURTZOVÁ, G. - Perforated mycotic aneurysm of the aortic arch: surgical managements by hypothermia with circulatory arrest. J. Cardiovasc. Surg., 28: 336-338, 1987.

5 SCHIEKEN, L. S.; BRENNER, J. I.; BAKER, K. R.; PACIFICO, A. - Aneurysm of the ascending aorta associated with sternal cleft cutaneous hemangioma, and occlusion of the right innominate artery in a neonate. Am. Heart. J., 113: 202-204, 1987.

6 ZUMBRO, G. L.; HENLEY, L. B.; TREASURE, R. L. - Saccular aneurysm of ascending aorta caused by granulomatous aortitis in a child. J. Thorac. Cardiovasc. Surg., 69: 397-401, 1975. 